\title{
Efficiency in the Australian stock market, 1875-2006: A note on extreme long-run random walk behaviour
}

\author{
Andrew C. Worthington ${ }^{\mathrm{a},{ }^{*}}$ and Helen Higgs ${ }^{\mathrm{b}}$ \\ ${ }^{a}$ University of Wollongong, Wollongong, Australia \\ ${ }^{\mathrm{b}}$ Griffith University, Meadowbrook, Australia
}

\begin{abstract}
This note examines the weak-form market efficiency of the Australian stock market. Daily returns from 6 January 1958 to 12 April 2006 and monthly returns from February 1875 to December 2005 are examined for random walks using serial correlation coefficient and runs tests, Augmented Dickey-Fuller, Phillips-Perron and Kwiatkowski, Phillips, Schmidt and Shin unit root tests and multiple variance ratio tests. The serial correlation tests indicate inefficiency in daily returns and borderline efficiency in monthly returns, while the runs tests conclude that both series are weak-form inefficient. The unit root tests suggest weak-form inefficiency in both return series. The results of the more stringent and least restrictive variance ratio tests indicate that the monthly returns series is characterised by a homoskedastic random walk, but the daily series violates weak-form efficiency because of the short-term autocorrelation in returns.
\end{abstract}

\section{Introduction}

Study of the stock return generating process has long been dominated by interest in its random walk properties. Justification for such interest is not hard to find, given that the presence (or absence) of a random walk has important implications for investors and trading strategies, fund managers and asset pricing models, and capital markets and market efficiency. Trading strategies, for example, differ when returns are characterised by random walks or by positive autocorrelation (or persistence) over short horizons and negative autocorrelation (or mean reversion) over long horizons. In this instance, and as the investment horizon lengthens, an investor would invest more (less) in stocks if the relative risk aversion is greater (less) than unity, than if the returns were serially independent.

Similarly, random walks in stock returns are crucial to the formulation of rational expectations models and the testing of (weak-form) market efficiency. In an efficient market the prices of stocks fully incorporate all relevant information and hence stock returns will display unpredictable behaviour. In stock prices not characterised by a random walk, the return generating process is dominated by a temporary component and therefore future returns can be predicted by the historical sequence of returns. Lastly, the ability of stock markets to

\footnotetext{
* Corresponding author. E-mail: andreww@uow.edu.au
} 
play the role that is ascribed to them - attracting foreign investment, boosting domestic saving and improving the pricing and availability of capital - depends upon the presence of random walks. A market following a random walk is consistent with equity being appropriately priced at an equilibrium level, whereas the absence of a random walk infers distortions in the pricing of capital and risk. This has important implications for the allocation of capital within an economy and hence overall financial development.

This note examines the long-run random walk behaviour of the Australian stock market. For the most part, previous research in this particular market has relied upon single, often inexact, testing procedures and/or employs limited time series data [see, for example, Groenewold and Kang (1993), Huang (1995), Groenwewold and Ariff (1998)]. This note employs a number of alternative, though complementary, testing procedures and the longest available series of monthly and daily prices. The remainder of the paper is divided into four main areas. Section II provides a description of the data employed in the analysis. Section III discusses the empirical methodology used. The results are dealt with in Section IV. The paper ends with some concluding remarks in Section V.

\section{Description and Properties of the Data}

The data employed in the study are closing prices from the Australian Stock Exchange for two overlapping sample periods and two different sampling frequencies. The less frequent, older price series is from February 1875 to December 2005 and includes 1,576 end-of-month observations. The more frequent, recent price series runs from 6 January 1958 to 12 April 2006 encompassing 12,520 end-of-day observations. These samples comprise the longest periods for which the respective monthly and daily prices are available. The capitalizationweighted All Ordinaries Price Index (since 1979) and its predecessor from the Sydney stock exchange (until 1979) are used. The long-term index includes base recalculations by Global Financial Data (2006).

The natural $\log$ of the relative price is computed for the monthly and daily intervals to produce a time series of continuously compounded returns, such that $r_{t}=\log \left(p_{t} / p_{t-1}\right) \times 100$, where $p_{t}$ and $p_{t-1}$ represent the stock index price at time $t$ and $t-1$, respectively. Table 1 presents a summary of descriptive statistics of the monthly and daily returns. Sample and annualised means, maximums, minimums, standard deviations, skewness, kurtosis and Jacque-Bera statistics and $p$-values are reported.

\section{$<$ TABLE 1 HERE $>$}

By and large, the distributional properties of both return series appear non-normal. Both series are significantly negatively skewed, indicating the greater probability of large deceases in returns than rises. The kurtosis, or degree of excess, in both return series is also significantly large, thereby indicating leptokurtic distributions with many extreme 
observations. Finally, the calculated Jarque-Bera statistics and corresponding p-values in Table 1 are used to test the null hypotheses that the monthly and daily distribution of market returns is normally distributed. All $p$-values are smaller than the .01 level of significance suggesting the null hypothesis can be rejected. None of these market returns are then well approximated by the normal distribution.

\section{Empirical Methodology}

\section{Random walk hypothesis}

Consider the following random walk with drift process:

$$
p_{t}=p_{t-1}+\beta+\varepsilon_{t}
$$

or

$$
r_{t}=\Delta p_{t}=\beta+\varepsilon_{t}
$$

where $p_{t}$ is the logarithm of the price index observed at time $t, \beta$ is an arbitrary drift parameter, $r_{t}$ is the change in the index and $\varepsilon_{t}$ is a random disturbance term satisfying $\mathrm{E}\left(\varepsilon_{t}\right)=$ $0, \sigma_{\varepsilon}^{2}$ is constant and $\mathrm{E}\left(\varepsilon_{t} \varepsilon_{t-g}\right)=0$, where $g \neq 0$, for all $t$. Under the random walk hypothesis, a market is (weak-form) efficient if the most recent price contains all available information and therefore the best predictor of future prices is the most current price. In the strictest version of the efficient market hypothesis, $\varepsilon_{t}$ is not only random and stationary, but exhibits no autocorrelation, since the disturbance term cannot possess any systematic forecast errors.

Accordingly, and despite its apparent singularity, the random walk model actually comprises three successively more restrictive hypotheses with sequentially stronger tests for random walks (Campbell et al., 1997; Fama, 1970; 1991). The more restrictive of these is that in a market that complies with a random walk it is not possible to use information on past prices to predict future prices (hereafter RW1). That is, returns in a market conforming to RW1 are serially uncorrelated, corresponding to a random walk hypothesis with dependent but uncorrelated increments. Parametric serial correlation tests of independence and nonparametric runs tests can be used to test for serial dependence.

However, it may still be possible for information on the variance of past prices to predict the future volatility of the market. A market that conforms to these conditions implies that returns are serially uncorrelated, corresponding with a random walk hypothesis with increments that are independent but not identically distributed (hereafter RW2). Unit root tests can be used to determine if the series is difference or trend non-stationary as a necessary condition for a random walk.

Finally, if it is not possible to predict either future price movements or volatility on the basis of information from past prices, then such a market complies with the least restrictive notion of a random walk (hereafter RW3). In such a market, returns are serially uncorrelated and conform to a random walk hypothesis with independent and identically distributed 
increments. Multiple variance ratio tests can focus attention on the uncorrelated residuals in the series, under assumptions of both homoskedastic and heteroskedastic random walks.

\section{Serial dependence tests}

Two approaches are employed to test for serial dependence in the returns. First, the serial correlation coefficient test is a widely employed procedure that tests the relationship between returns in the current period and those in the previous period. If no significant autocorrelations are found then the series are assumed to follow a random walk. Second, the runs test determines whether successive price changes are independent and unlike the serial correlation test of independence, is non-parametric and does not require returns to be normally distributed. Observing the number of 'runs' - or the sequence of successive price changes with the same sign - in a sequence of price changes tests the null hypothesis of randomness. To perform this test $A$ is assigned to each return that equals or exceeds the mean value and $B$ for the items that are below the mean. Let $n_{A}$ and $n_{B}$ be the sample sizes of items $A$ and $B$ respectively. The test statistic is $U$, the total number of runs. For a large sample, that is where both $n_{A}$ and $n_{B}$ are greater than twenty, the test statistic is approximately normally distributed:

$$
Z=\frac{U-\mu_{U}}{\sigma_{U}}
$$

where

$$
\mu_{\mathrm{U}}=\frac{2 n_{A} n_{B}}{n}+1, \quad \sigma_{U}=\sqrt{\frac{2 n_{A} n_{B}\left(2 n_{A} n_{B}-n\right)}{n^{2}(n-1)}} \text { and } n=n_{A}+n_{B}
$$

\section{Unit root tests}

Three different unit root tests are used to test the null hypothesis of a unit root: namely, the Augmented Dickey-Fuller (ADF) test (1979), the Phillips-Peron (PP) test (1988), and the Kwiatkowski, Phillips, Schmidt and Shin (KPSS) test (1992). These correspond to tests of the next to most restrictive random walk hypothesis (RW2). To start with, the well-known ADF unit root test of the null hypothesis of nonstationarity is conducted in the form of the following regression equation:

$$
\Delta p_{i t}=\alpha_{0}+\alpha_{1} t+\rho_{0} p_{i t-1}+\sum_{i=1}^{q} \rho_{i} \Delta p_{i t-i}+\varepsilon_{i t}
$$

where $p_{i t}$ denotes the logarithm of the price for the $i$-th market at time $t, \Delta p_{i t}=p_{i t}-p_{i t-1}, \rho$ are coefficients to be estimated, $q$ is the number of lagged terms, $t$ is the trend term, $\alpha_{1}$ is the estimated coefficient for the trend, $\alpha_{0}$ is the constant, and $\varepsilon$ is white noise. MacKinnon's critical values are used in order to determine the significance of the test statistic associated with $\rho_{0}$.

The PP incorporates an alternative (nonparametric) method of controlling for serial correlation when testing for a unit root by estimating the non-augmented Dickey-Fuller test 
equation and modifying the test statistic so that its asymptotic distribution is unaffected by serial correlation. Finally, the KPSS uses a similar (though parametric) autocorrelation correction to the PP but assumes that the observed time series can be decomposed into the sum of a deterministic trend, a random walk with zero variance and a stationary error term. It thus tests the null hypothesis of trend stationarity corresponding to the hypothesis that the variance of the random walk equals zero.

Of course, it is well known that ADF unit root tests fail to reject the null hypothesis of a unit root for many time series, and that allowing for error autocorrelation using the PP test does not necessarily improve these results. However, the KPSS test complements the standard unit root tests since it can distinguish between the logarithm of the prices that appear to be stationary, those that appear to have a unit root, and those that are not sufficiently informative to be sure whether they are either.

\section{Multiple variance ratio tests}

The multiple variance ratio (MVR) test as proposed by Chow and Denning (1993) is used to detect autocorrelation and heteroskedasticity in the returns. Based on Lo and MacKinlay's (1988) single variance ratio (VR) test, Chow and Denning (1993) adjust the focus from a specific interval to one more consistent with the random walk hypothesis by means of covering all possible intervals. As shown by Lo and MacKinlay (1988), the variance ratio statistic is derived from the assumption of linear relations in observation interval regarding the variance of increments. If a series follows a random walk process, the variance of a $q$ thdifferenced variable is $q$ times as large as the first-differenced variable. For a series partitioned into equally spaced intervals and characterised by random walks, one $q$ th of the variance of $\left(p_{t}-p_{t-q}\right)$ is expected to be the same as the variance of $\left(p_{t}-p_{t-1}\right)$ :

$$
\operatorname{Var}\left(p_{t}-p_{t-q}\right)=q \operatorname{Var}\left(p_{t}-p_{t-1}\right)
$$

where $q$ is any positive integer. The variance ratio is then denoted by:

$$
\operatorname{VR}(q)=\frac{\frac{1}{q} \operatorname{Var}\left(p_{t}-p_{t-q}\right)}{\operatorname{Var}\left(p_{t}-p_{t-1}\right)}=\frac{\sigma^{2}(q)}{\sigma^{2}(1)}
$$

such that under the null hypothesis $V R(q)=1$. Chow and Denning (1993) then generate a procedure for the multiple comparison of the set of variance ratio estimates with unity. For a single variance ratio test, under the null hypothesis, $V R(q)=1$, hence $M_{r}(q)=V R(q)-1=0$. Consider a set of $m$ variance ratio tests $\left\{M_{r}\left(q_{i}\right) \mid i=1,2, \ldots, m\right\}$. Under the random walk null hypothesis, there are multiple sub-hypotheses: $H_{o i}: M_{r}\left(q_{i}\right)=0$ for $i=1,2, \ldots, m$ and $H_{1 i}: M_{r}\left(q_{i}\right)$ $\neq 0$ for any $i=1,2, \ldots, m$. The rejection of any one or more $H_{o i}$ rejects the random walk null hypothesis. For a set of test statistics, say $Z(q),\left\{Z\left(q_{i}\right) \mid i=1,2, \ldots, m\right\}$, the random walk null hypothesis is rejected if any one of the estimated variance ratio is significantly different from one. Chow and Denning (1993) control the size of the MVR test by comparing the calculated 
values of the standardized test statistics, either $Z(q)$ or $Z^{*}(q)$ with the Standardized Maximum Modulus $(S M M)$ critical values where $Z_{\alpha^{*} / 2}$ and $\alpha^{*}=1-(1-\alpha)^{1 / m}$. If the maximum absolute value of $Z(q)$ is greater than the $S M M$ critical value than the random walk hypothesis is rejected.

\section{Empirical Results}

Table 2 presents the tests of independence: namely, the serial correlation and runs tests. The null hypothesis of no serial correlation for the daily returns is rejected at the .01 level but fails to be rejected, albeit borderline, for the monthly returns. We may conclude the daily return series is weak-form inefficient given the significance of the autocorrelation coefficient. In both cases, the coefficients are positive indicating persistence in returns, with persistence being higher in the daily returns (0.1630) than in the monthly returns $(0.0410)$. In terms of the runs tests, the negative $z$-values for both return series indicates that the actual number of runs falls short of the expected number of runs under the null hypothesis of return independence at the .01 level. These also indicate positive serial correlation.

\section{$<$ TABLE 2 HERE $>$}

Table 3 illustrates the unit root tests, comprising the ADF and PP $t$-statistics and $p$-values and the KPSS $L M$-statistic and asymptotic significance at the level and difference series of the logarithm of prices. In the case of the former the null hypothesis of a unit root is tested against the alternative of no unit root (stationary). For the latter, the null hypothesis of no unit root is tested against the alternative of a unit root (non-stationary). At levels, the ADF and PP $t$ statistics fail to reject the null hypotheses of a unit root at the 0.10 level of significance, thereby indicating that both of the logarithms of the price series examined are non-stationary. For the KPSS tests of the null hypothesis of no unit root, the $L M$-statistic exceeds the asymptotic critical value at the .10 level for the monthly and daily level series, also indicating non-stationarity.

\section{$<$ TABLE 3 HERE $>$}

However, the null hypotheses for the ADF and PP unit root tests are rejected at the 0.01 level for the monthly and daily difference series indicating stationarity. The KPSS fail to rejects the null hypothesis for the differences series, also suggesting stationarity. As a necessary condition for a random walk, the ADF and PP unit root tests rejected the requisite null hypothesis of non-stationarity for both the monthly and daily prices, while the KPSS unit root test failed to reject stationarity for monthly returns. Since the ADF, PP and KPSS tests reject the presence of unit roots (non-stationarity), there is no evidence for weak-form efficiency in either series. That said, since it is well known that unit root tests have very poor power properties, a preferred alternative is multiple variance ratio tests. 
Table 4 presents the results of the multiple variance ratio tests of returns in both return series. The sampling intervals are 2, 6, 12 and 24 months for the monthly series and 2, 5, 10 and 20 days, corresponding to one day, one week, one fortnight and one month calendar periods in the daily series. For each interval Table 4 presents the estimates of the variance ratio $V R(q)$ and the test statistics for the null hypotheses of homoskedastic, $Z(q)$ and heteroskedastic, $Z^{*}(q)$ increments random walk. Under the multiple variance ratio procedure, only the maximum absolute values of the test statistics are examined. For sample sizes exceeding at least the number of daily observations and where $m=4$, the critical value for these test statistics is 2.49 at the .05 level of significance. For each set of multiple variance ratio tests, an asterisk denotes the maximum absolute value of the test statistic that exceeds this critical value and thereby indicates whether the null hypothesis of a random walk is rejected.

\section{$<$ TABLE 4 HERE $>$}

Consider the results for monthly returns. The null hypothesis that monthly market returns follow a homoskedastic random walk fails to be rejected at $Z(12)=1.9168$. Failure to reject the null hypothesis of a random walk under homoskedasticity for a 12-month period is also a test of the null hypothesis of a homoskedastic random walk under the alternative sampling periods and we may therefore conclude that Australian monthly stock returns from 1875 to 2005 follow a random walk. Now consider the daily returns. Since these reject the null hypothesis of a random walk at $\mathrm{Z}(2)=18.2587$ over a two-day period they also reject the null hypotheses over the weekly, monthly and yearly sampling periods and we may conclude that daily returns in Australia from 1958 to 2006 do not follow a random walk. However, rejection of the null hypothesis under homoskedasticity could result from heteroskedasticity and/or autocorrelation in the return series. After a heteroskedastic-consistent statistic is calculated, the null hypothesis is also rejected at $\mathrm{Z}^{*}(2)=7.1218$. The heteroskedastic random walk hypothesis is thus rejected because of autocorrelation in the daily increments of the returns on the Australian market. We may conclude that the Australian stock market is not weak form efficient using daily returns over the period 1958 to 2006.

Further, Lo and MacKinlay (1988) show that for $q=2$, estimates of the variance ratio minus one and the first-order autocorrelation coefficient estimator of price changes are asymptotically equal [the serial correlation coefficient in Table 2 is 0.0410 for monthly returns and 0.1630 for daily returns]. On this basis, the estimated first-order autocorrelation coefficient is 0.0423 corresponding to the estimated variance ratio $V \hat{R}(2)$ of 1.0423 (i.e. 1.0423 - 1) for monthly returns and 0.1632 for daily returns (i.e. 1.1632 - 1). In addition, when $V \hat{R}(2)>1$ persistence is suggested, this indicates there is positive autocorrelation in Australian equity returns over the long monthly and daily horizons. 


\section{Concluding Remarks}

This paper examines the weak form market efficiency of the Australian stock market. Two sample frequencies and periods are included: a longer monthly series from 1875 to 2005 (130 years) and a shorter daily series from 1958 to 2006 (48 years). Three different procedures are employed to test for random walks in monthly and daily returns: (i) the parametric serial correlation coefficient and the nonparametric runs test are used to test for serial correlation (RW1); (ii) Augmented Dickey-Fuller, Phillips-Perron and Kwiatkowski, Phillips, Schmidt and Shin unit root tests are used to test for non-stationarity as a necessary condition for a random walk (RW2); and (iii) multiple variance test statistics are used to test for random walks under varying distributional assumptions (RW3).

The results for the tests of serial correlation are in broad agreement, conclusively rejecting the presence of a random walk in daily and monthly returns. Similarly, the unit root tests conclude that unit roots, as minimum necessary conditions for a random walk, are absent in the differences of either series. Finally, the multiple variance ratio procedure conclusively rejects the presence of random walks in the daily series with the monthly series satisfying the most stringent random walk criteria. In this manner, the evidence provided by the more restrictive notions of a random walk (RW1 and RW2) has been refuted with evidence from the less restrictive notion of a random walk (RW3). We may conclude that monthly Australian returns from 1975 to 2005 follow a random walk, but that daily returns from 1958 to 2006 do not because of short-term (i.e. less than one month) autocorrelation in returns.

\section{References}

Andersen, T.G., Bollerslev, T. and Das, A. (2001) Variance ratio statistics and high-frequency data: Testing for changes in intraday volatility patterns, Journal of Finance, 56, 305-327.

Campbell, J.Y., Lo, A.W. and MacKinlay, A.C. (1997) The Econometrics of Financial Markets, Princeton University Press, Princeton.

Chow. K.V., and Denning, K. (1993) A simple multiple variance ratio test, Journal of Econometrics, 58, 385401.

Dickey, D.A., and Fuller, W.A. (1979) Distribution of the estimators for autoregressive time series with a unit root, Journal of the American Statistical Association, 74, 427-431.

Fama, E. (1970) Efficient markets: A review of theory and empirical work, Journal of Finance, 25, 1181-1185.

Fama, E. (1991) Efficient capital markets II, Journal of Finance, 46, 1575-1617.

Groenewold, N., and Kang, K.C. (1993) The semi-strong efficiency of the Australian share market, The Economic Record, 69, 405-410.

Groenewold, N., and Ariff, M. (1998) The effects of deregulation on share market efficiency in the Asia-Pacific, International Economic Journal, 12, 23-47.

Huang, B.N. (1995) Do Asian stock markets follow random walks? Evidence from the variance ratio test, Applied Financial Economics, 5, 251-256.

Kwiatkowski, D., Phillips, P.C.B., Schmidt, P. and Shin, Y. (1992) Testing the null hypothesis of stationarity against the alternative of a unit root, Journal of Econometrics, 54, 159-178.

Lo, A., and MacKinlay, A.C. (1988) Stock market prices do not follow random walks: Evidence from a simple specification test, Review of Financial Studies, 1, 41-66.

Los, C.A. (2000) Nonparametric efficiency testing of Asian stock markets using weekly data, chapter in Advances in Econometrics, Vol. 14, JAI Press, Stanford.

Phillips, P.C.B., and Perron, P. (1988) Testing for a unit root in time series regression, Biometrika, 75, 335-346.

Ronen, T. (1997) Tests and properties of variance ratios in microstructure studies, Journal of Financial and Quantitative Analysis, 32, 183-204. 
Table 1. Descriptive statistics for Australian monthly and daily market returns

\begin{tabular}{lrcrrrrrrrrrr}
\hline \multirow{2}{*}{ Frequency } & \multirow{2}{*}{ Start } & \multirow{2}{*}{ End } & Observations & Mean & $\begin{array}{c}\text { Annualised } \\
\text { mean }\end{array}$ & Maximum & Minimum & Std. Dev. Skewness & Kurtosis & Jarque-Bera & JB & S-value \\
\hline Monthly & 28-Feb-1875 & 30-Dec-2005 & 1575 & 0.4407 & 5.418 & 21.7020 & -55.2449 & 3.8636 & -1.9456 & 33.4776 & $6.20 \mathrm{E}+04$ & 0.0000 \\
Daily & 6-Jan-1958 & 12-Apr-2006 & 12519 & 0.0284 & 7.357 & 7.0162 & -28.7611 & 0.8260 & -3.7630 & 128.7614 & $8.28 \mathrm{E}+06$ & 0.0000 \\
\hline
\end{tabular}

Notes: JB - Jarque-Bera. Critical values for significance of skewness and kurtosis respectively at the .05 level are 0.0617 and 0.1234 for monthly returns and 0.0218 and 0.0437 for daily returns. The annualised mean for daily returns assumes 250 trading days per year.

\section{Table 2. Independence tests for Australian monthly and daily market returns}

\begin{tabular}{|c|c|c|c|c|c|c|c|c|c|}
\hline \multirow[b]{2}{*}{ Frequency } & \multicolumn{3}{|c|}{ Serial correlation } & \multicolumn{5}{|c|}{ Runs test } & \multirow[b]{2}{*}{$p$-value } \\
\hline & Coefficient & $p$-value & Mean & $\begin{array}{c}\text { Cases }< \\
\text { mean }\end{array}$ & $\begin{array}{c}\text { Cases } \geq \\
\text { mean }\end{array}$ & $\begin{array}{l}\text { Total } \\
\text { cases }\end{array}$ & $\begin{array}{c}\text { Number } \\
\text { of runs }\end{array}$ & $Z$-value & \\
\hline Monthly & 0.0410 & 0.1038 & 0.4407 & 766 & 809 & 1575 & 700 & -4.4351 & 0.0000 \\
\hline Daily & 0.1630 & 0.0000 & 0.0284 & 6355 & 6164 & 12519 & 5086 & -20.9738 & 0.0000 \\
\hline
\end{tabular}

Table 3. Unit root tests for Australian monthly and daily market returns

\begin{tabular}{|c|c|c|c|c|c|c|c|c|c|c|c|c|}
\hline \multirow[b]{2}{*}{ Market } & \multicolumn{2}{|c|}{ Level } & \multicolumn{2}{|c|}{ Difference } & \multicolumn{2}{|c|}{ Level } & \multicolumn{2}{|c|}{ Difference } & \multicolumn{2}{|c|}{ Level } & \multicolumn{2}{|c|}{ Difference } \\
\hline & $\underset{t \text {-statistic }}{\mathrm{ADF}}$ & $\begin{array}{c}\text { ADF } \\
p \text {-value }\end{array}$ & $\begin{array}{c}\mathrm{ADF} \\
t \text {-statistic }\end{array}$ & $\begin{array}{c}\text { ADF } \\
p \text {-value }\end{array}$ & $\begin{array}{c}\mathrm{PP} \\
t \text {-statistic }\end{array}$ & $\begin{array}{c}\text { PP } \\
p \text {-value }\end{array}$ & $\begin{array}{c}\mathrm{PP} \\
t \text {-statistic }\end{array}$ & $\begin{array}{c}\mathrm{PP} \\
p \text {-value }\end{array}$ & $\begin{array}{c}\text { KPSS } L M- \\
\text { statistic }\end{array}$ & $\begin{array}{c}\text { KPSS } \\
\text { significance }\end{array}$ & $\begin{array}{l}\text { KPSS } L M- \\
\text { statistic }\end{array}$ & $\begin{array}{c}\text { KPSS } \\
\text { significance }\end{array}$ \\
\hline Monthly & -2.1146 & 0.5367 & -38.0824 & 0.0000 & -2.2385 & 0.4672 & -38.0880 & 0.0000 & 0.7999 & 0.0100 & 0.0182 & \\
\hline
\end{tabular}

Notes: The Augmented Dickey-Fuller (ADF) test hypotheses are $\mathrm{H}_{0}$ : unit root, $\mathrm{H}_{1}$ : no unit root (stationary). The lag orders in the ADF equations are determined by the significance of the coefficient for the lagged terms. Intercepts only in the series. The Phillips-Peron (PP) unit root test hypotheses are $\mathrm{H}_{0}$ : unit root, $\mathrm{H}_{1}$ : no unit root (stationary). Intercepts only in the series. The Kwiatkowski, Phillips, Schmidt and Shin (KPSS) unit root test hypotheses are $\mathrm{H}_{0}$ : no unit root (stationary), $\mathrm{H}_{1}$ : unit root. The asymptotic critical values for the KPSS LM test statistic at the $.10, .05$ and .01 levels are $0.1190,0.1460$ and 0.2160 respectively.

Table 4. Multiple variance ratio tests for Australian monthly and daily market returns

\begin{tabular}{lcccccrrr}
\hline \multicolumn{1}{c}{ Monthly } \\
\hline Statistics & $q=2$ & $q=6$ & $q=12$ & $q=24$ & $q=2$ & $q=5$ & $q=10$ & $q=20$ \\
\hline $\mathrm{VRq}$ & 1.0423 & 1.0865 & 1.1811 & 1.1800 & 1.1632 & 1.3253 & 1.4946 & 1.7743 \\
$\mathrm{Zq}$ & 1.6800 & 1.3886 & 1.9168 & 1.3033 & $* 18.2587$ & 16.6140 & 16.3893 & 17.4309 \\
$\mathrm{Z} q \mathrm{q}$ & 1.1140 & 0.8889 & 1.2465 & 0.9053 & $* 7.1218$ & 6.2654 & 5.8359 & 6.5270 \\
\hline Notes: VR(q) - variance ratio estimate, Z(q) - test statistic for null hypothesis of \\
homoskedastic increments random walk, Z* (q) - test statistic for null hypothesis of \\
heteroskedastic increments random walk; the critical value for Z(q) and Z*(q) at the 5 \\
percent level of significance is 2.49, an asterisk indicates significance at this level; \\
Sampling intervals (q) are in months for the monthly series and days for the daily series.
\end{tabular}

